\title{
Induction of remission in a patient with Takayasu's arteritis by low dose pulses of methotrexate
}

\author{
Dror Mevorach, Gil Leibowitz, Meyer Brezis, Eyal Raz
}

\begin{abstract}
A 42 year old woman with Takayasu's arteritis responded to treatment with prednisone (60 mg daily) but developed severe side effects. Cyclophosphamide treatment did not produce a clinical improvement or steroid sparing effect. A treatment trial with a weekly pulse of low dose methotrexate improved her symptoms and the patency of her occluded left subclavian artery.
\end{abstract}

(Ann Rheum Dis 1992; 51: 904-905)

Takayasu's arteritis is a disease of unknown aetiology characterised by inflammation and stenosis of the aortic arch and its major branches. ${ }^{1}$ Corticosteroids are the cornerstone of treatment of Takayasu's disease, though not always effective. ${ }^{2}$ Other modalities, including cyclophosphamide, ${ }^{2}$ vascular surgery, ${ }^{3}$ and percutaneous transluminal angioplasty, ${ }^{4}$ are also important.

Methotrexate has become popular in the last decade for the treatment of various rheumatic and immune related diseases, especially rheumatoid arthritis. ${ }^{5}$ Its effectiveness in Takayasu's arteritis is unknown. We describe here a patient who responded dramatically to treatment with low doses of methotrexate after failure of treatment with cyclophosphamide.

\section{Case report}

A 42 year old woman was admitted to hospital with a one month history of progressive myalgia, inability to walk, and fever. She also had jaw claudication, night sweats, Raynaud's phenomenon, temporal headache, and weight loss. Physical examination showed a blood pressure of $180 / 120 \mathrm{mmHg}$ in the right arm. The left brachial and radial pulse were hardly palpable. Murmurs were audible over the carotid and left subclavian arteries. The proximal muscles of her arms and legs were tender. Relevant laboratory tests showed an erythrocyte sedimentation rate of $100 \mathrm{~mm} /$ hour. Her differential blood count, electrolytes, and muscle enzymes were normal, as were the results of kidney, liver, and thyroid function tests. Antinuclear factor was positive ( +3 on a $1-4$ scale), and tests for antibodies to DNA, rheumatoid factor, and the Venereal Disease Research Laboratory (VDRL) test were negative. An electromyogram and a temporal artery biopsy sample were normal. Angiography showed mild stenosis of the right subclavian and carotid arteries, severe stenosis of the proximal left subclavian artery, and ectasia of the inominate artery with normal aortic arch. Takayasu's arteritis was diagnosed and prednisone (60 mg daily) was started.
Four months of treatment with steroids gave a marked improvement of the patient's symptoms. Her walking was easier and she could perform domestic duties without muscular pain. Severe adverse reactions were noted, however, including a Cushingoid appearance, obesity, hirsutism, emotional lability, and depression. The patient could not tolerate this mode of treatment and cyclophosphamide $150 \mathrm{mg}$ daily was started. This treatment was given for four months without any clinical improvement. Whenever the prednisone dose was decreased to $30 \mathrm{mg}$ daily, the disease flared up with severe myalgia and fever up to $40^{\circ} \mathrm{C}$. Doppler ultrasound showed complete obstruction of the previously stenosed left subclavian artery with 'steal' from the vertebral arteries. Cyclophosphamide was stopped and pulsed methotrexate $15 \mathrm{mg}$ weekly was started.

During the ensuing four months prednisone was tapered to $5 \mathrm{mg}$ daily with resolution of her symptoms. The left radial pulse was markedly improved on palpation and Doppler ultrasound showed the disappearance of the 'steal' from the vertebral arteries with a relatively patent left subclavian artery. The other vascular lesions were unchanged.

\section{Discussion}

Corticosteroids are considered the treatment of choice for patients with Takayasu's arteritis. A therapeutic response to steroids has been reported in $100 \%$ of the patients in one study. ${ }^{6}$ Other studies reported a much lower response rate. $^{2} 7$ The part played by cytotoxic drugs in the treatment of Takayasu's arteritis is controversial. Some workers believe that it is not necessary to consider any drugs other than corticosteroids, ${ }^{8}$ whereas others advocate cytotoxic treatment, especially cyclophosphamide, if the disease is unresponsive to steroid treatment. ${ }^{2}$

Low doses of methotrexate have been used in the treatment of rheumatoid arthritis, ${ }^{5}$ severe steroid dependent asthma, ${ }^{9}$ and primary biliary cirrhosis. ${ }^{10} \mathrm{We}$ are aware of only one other case of successful treatment with methotrexate in Takayasu's arteritis. ${ }^{11}$

This report is of special interest for several reasons. First, it shows for the first time that methotrexate can improve vascular lesions in Takayasu's arteritis. Second, it shows that this drug can induce and maintain clinical remission in this disease. Third, methotrexate was more effective than cyclophosphamide in the treatment of Takayasu's arteritis, an advantage because of the fewer known side effects, especially with respect to oncogenicity. ${ }^{12}$ 
We suggest that methotrexate can be used as a first line drug in the treatment of Takayasu's arteritis due to its effectiveness and relatively low toxicity. Meanwhile, double blind, controlled studies are warranted to determine its efficacy in the treatment of giant cell arteritides.

1 Fauci A S, Haynes B F, Katz P. The spectrum of vasculitis: clinical, pathologic, and therapeutic considerations. An Intern Med 1978; 89: 660-76.

2 Shelhamer J H, Volvman D J, Parrillo J E, Lawley T J Johnston M R, Fauci A S. Takayasu's arteritis and its therapy. Ann Intern Med 1985; 103: 121-6.

3 Takagi A, Tada Y, Sato O, Miyata T. Surgical treatment for Takayasu's arteritis. A long term follow-up study. T Cardiovasc Surg 1989; 30: 553-8.

J Cardiovasc Surg 1989; 30: 553-8.
4 Park J H, Han M C, Kim S H, Oh B H, Park Y B, Seo J D. Takayasu arteritis: angiographic findings and results of

5 Kremer J M, Lee J K. The safety and efficacy of the use of methotrexate in long term-therapy for rheumatoid arthritis. Arthritis Rheum 1986; 29: 822-31.

6 Fraga A, Mintz G, Valle L, Flores-Izquierdo G. Takayasu's arteritis: frequency of systemic manifestations (study of 22 patients) and favorable (12 maintenance steroid 1972; 15: 617-24.

7 Lupi-Herrera E, Sanchez-Torres G, Maarcushamer J, Mispireta J, Horowitz S, Vela J E. Takayasu's arteritis: clinical study of 107

8 Hall S, Barr W, Lie J T, Stanson A W, Kazmier F J, Hunder G G. Takayasu arteritis: a study of 32 North American patients. Medicine (Baltimore) 1985; 64: 89-99.

9 Mullarkey M F, Bluminstein B A, Andrade W P, Bailey G A, Olasen I, Wetzel G E. Methotrexate in the treatment of corticosteroid-dependent asthma: a double blind crossover study. N Engl f Med 1988; 318: 603-7.

10 Kaplan M M, Kenox T A, Arora S. Primary biliary cirrhosis treated with low-dose oral pulse methotrexate. Ann Intern Med 1988; 109: 429-31.

11 Liang G C, Memckas R, Madayag M. Multiple percutaneous transluminal angioplasties and low dose pulse methotrexate transluminal angioplasties and low dose pulse methotrexate

12 Weinstein G. Psoriasis-liver-methotrexate interactions: results of an international cooperative study. Arch Dermatol 1973; 108: $36-42$. 